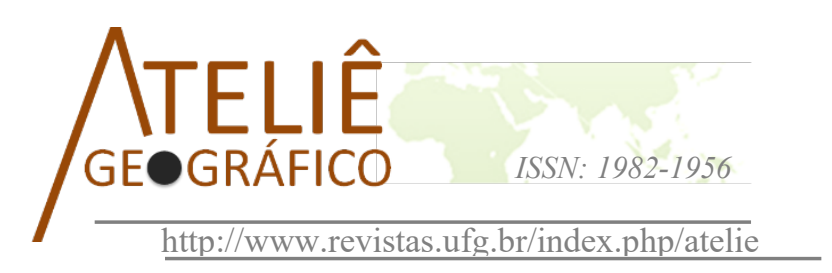

\title{
Apontamentos a partir de algumas considerações de Marx e Engels em relação às noções de Homem, Natureza e Alienação
}

\author{
Notes from some considerations of Marx and Engels in \\ relation to the notions of Man, Nature and Alienation
}

\section{Notas sobre algunas consideraciones de Marx y Engels en relación con las nociones de Hombre, Naturaleza y Alienación}

\author{
Douglas Santos \\ Universidade Federal da Grande Dourados (prof. colaborador) \\ Universidade Pedagógica de Moçambique (prof. visitante) \\ douglassangeog@gmail.com
}

\begin{abstract}
Resumo
Homem, natureza e alienação é uma articulação temática que pode ser encontrada com alguma facilidade nas obras de Marx e Engels e, por isso mesmo, de maneira isolada ou igualmente articulada, são temas reincidentes entre comentadores do conjunto da obra dos chamados "criadores do materialismo histórico e dialético". Nesse artigo, evitando dialogar diretamente com esses comentadores, nos dedicamos somente a exercitar o desvendamento de algum tipo de articulação que, imaginamos, se encontra no interior de fragmentos de obras produzidas pelo próprio Marx em momentos muito diferentes de sua vida e em um único texto de Engels. O objetivo central do presente artigo é evidenciar a necessidade de comentar esses autores retomando diretamente seus textos e, marginalmente, propor alguma reflexão que nos permita amadurecer a possível relação entre as obras que nos serviram de apoio e o desenrolar hodierno do pensamento geográfico.
\end{abstract}

Palavras-chave: Marx, Engels, Natureza, Sociedade, Alienação, Geografia.

\begin{abstract}
Man, nature and alienation are a thematic articulation easily found in Marx and Engels' works and because of this, isolated or articulated, are themes often discussed by the commentators of the "creators of historic and dialectical materialism" works. This paper avoids directly discuss with these commentators, dedicating only to exercise the unveiling some kind of articulation, that, in our view, is in some fragments of works produced by Marx, in different moments of his life, and in one unique text of Engels.
\end{abstract}


The main objective is evidencing the necessity of resume directly the author's texts to comment, and aims to propose some reflection, to mature the possible relation between our base works and the today development of geographic thinking.

Keyword: Marx, Engels, Nature, Society, Alienation, Geography.

\begin{abstract}
Resumen
El hombre, la naturaleza y la enajenación es una articulación temática que se puede encontrar con cierta facilidad en las obras de Marx y Engels y, por esta misma razón, de manera aislada o igualmente articulada, son temas recurrentes entre los comentaristas del trabajo de los llamados "creadores del materialismo". histórico y dialéctico ". En este artículo, evitando dialogar directamente con estos comentaristas, nos dedicamos solo a revelar algún tipo de articulación que, imaginamos, se encuentra dentro de fragmentos de obras producidas por el propio Marx en momentos muy diferentes de su vida y, por fin en un solo texto de Engels. El objetivo principal de este artículo es resaltar la necesidad de comentar sobre estos autores, retomando directamente sus textos y, marginalmente, proponer alguna reflexión que nos permita madurar la posible relación entre las obras que sirvieron de apoyo a nuestra reflexión y el desarrollo actual del pensamiento geográfico.

Palabras clave: Marx, Engels, Naturaleza, Sociedad, Enajenación, Geografía.
\end{abstract}

\title{
Introdução
}

Revisitar textos de Marx com o objetivo de explicitá-los é uma tarefa já realizada à exaustão e, sem a menor dúvida, teve início com seu companheiro Engels, responsável que foi pela editoração da maior parte de $O$ Capital, elaboração de diferentes prefácios sobre o legado de seu amigo e profundamente dedicado ao desenvolvimento daquelas proposições no âmbito da explicitação da empiria. De toda maneira, tantos foram seus interpretadores que um outro subproduto foi paulatinamente construído: aqueles que se dedicaram a interpretar os interpretadores, apontar seus erros, evidenciar suas fragilidades. Sem dúvida, encontraremos em Lenin e Rosa de Luxemburgo os maiores expoentes desse tipo de exercício exegético, inclusive porque interpretar os interpretadores fazia parte da militância política na qual ambos se envolveram.

O passar dos séculos XIX e XX só fez ampliar a lista de detratores, defensores, defensores dos detratores, defensores dos defensores e assim por diante - e, diga-se de passagem, trata-se ainda de um esforço longe de seu fim e carregado de múltiplos significados, tanto para a militância política no seu sentido mais estrito (considerando a transmutação dos embates em torno da construção de uma proposição de sociedade para o combate puro e simples dos sintomas mais superficiais da sociedade capitalista, ou de um ativismo que toma como ponto de inflexão, inclusive, a defesa de uma natureza e de uma humanidade genéricas o suficiente para serem, de fato, vazias de significado), quanto, no limite, o que poderíamos chamar aqui de desenvolvimento do pensamento no campo da filosofia (apesar do mal-estar criado por Marx no que se costuma denominar de filosofia).

A proposição de colocar em discussão o significado de natureza e de homem no pensamento de Marx e/ou no marxismo está, certamente, associada a tais embate. Ter Marx como interlocutor, no entanto, é uma exigência carregada das dificuldades advindas 
da complexidade inerente à sua obra, que se desdobram ao infinito à medida que muitos de nós nos obrigamos a dialogar com um dos mais importantes analistas da sociedade capitalista e, conjuntamente, a incluir no desenvolvimento de nossos discursos as proposições feitas por seus comentadores. A tarefa, hercúlea por princípio, vai se tornando impossível no enredamento a que a bibliografia nos obriga.

O objetivo deste texto é evitar tais dificuldades enfrentando o tema ainda no limite imposto pelo diálogo direto com alguns textos da extensa obra de Marx. Limito-me a alguns porque, sem definir limites, a tarefa estaria muito além da minha capacidade. Procuro defender-me a partir da proposição feita por Montaigne que, em uma tradução livre, diz mais ou menos o seguinte: "Meu medo é o fato de termos os olhos maiores que o ventre e mais curiosidade que capacidade".

Assim, vamos à tarefa inicial de delimitar os termos do embate:

a. O ponto de partida da reflexão terá como referência a Crítica ao Programa de Gotha, principalmente os primeiros parágrafos, onde Marx procura explicitar, mais uma vez, suas noções de trabalho, riqueza e natureza.

b. O segundo movimento se fará com um texto cronologicamente mais antigo: os Manuscritos Econômicos e Filosóficos, principalmente trechos onde Marx coloca em discussão o sentido de alienação.

c. A seguir, em um outro salto cronológico, a inspiração ficará por conta dos Grundrisse e, no trecho sobre a teoria e o método em economia política, o apontamento estará voltado para o significado de "conhecimento".

d. Por fim, dedicaremos algumas páginas a uma rápida leitura do prefácio feito por Engels ao seu Dialética da Natureza.

Assim, procurando controlar tentações de todos os tipos, evitarei o uso de extensa bibliografia ou, o que seria pior, debater com tal emaranhado de ideias, posições e, principalmente, divagações que não sejam as de minha própria safra.

\section{Primeiro movimento: o trabalho humano é natureza em movimento}

[Programa de Gotha] "O trabalho é a fonte de toda a riqueza e de toda a cultura(...)"

[Comentários de Marx] O trabalho não é a fonte de toda a riqueza. A natureza é a fonte dos valores de uso (que são os que verdadeiramente integram a riqueza material!), nem mais nem menos que o trabalho, que não é mais que a manifestação de uma força natural, da força de trabalho do homem. Essa frase encontrase em todas as cartilhas e só é correta se se subentender que o trabalho é efetuado com os correspondentes objetos e Instrumentos. (...) $\mathrm{Na}$ medida em que o homem se situa de antemão como proprietário diante da natureza, primeira fonte de todos os meios e objetos de trabalho, e a trata como possessão sua, seu trabalho converte-se em fonte de valores de uso, e, portanto, em fonte de riqueza. (MARX, 1984) 
Não se trata aqui de explicar a proposição de Marx. Trata-se, na verdade, de extrair desses poucos parágrafos uma proposição, ou leitura, ou compreensão específica de Natureza e de Homem (obviamente, no sentido de humanidade) que, imagino, está definindo seu texto. Deixemos de lado, portanto, a quem interessa afirmar que o trabalho é a fonte de toda riqueza e os embates políticos/ideológicos que tudo isso carrega. Para o nosso tema, a chave da citação está no fato de Marx afirmar que a Natureza é a fonte dos valores de uso e que o trabalho humano redefine-se sob dois aspectos: primeiro, porque é a própria natureza em um de seus movimentos específicos; em segundo lugar, porque essa natureza, que é o trabalho humano, coloca à disposição da humanidade novos valores de uso e, portanto, redefine-se enquanto natureza. Trata-se do "estar deixando de estar" hegeliano, aqui já sob o crivo da crítica materialista.

Repetindo: trata-se de atentar à proposição que o trabalho seja, nem mais nem menos que a natureza, fonte dos valores de uso, considerando que aquele (o trabalho humano) é uma maneira de manifestação desta (a natureza). Repito para realçar a ideia já contida no parágrafo citado, que nos leva a um mergulho absolutamente radical ao considerarmos que homem e natureza não são dois elementos que se somam, mas que a humanidade, por ser natureza, com ela não se confunde, mas dela faz parte. Trata-se aqui de entendermos natureza na escala da universalidade e a humanidade na escala de uma das singularidades (da natureza). Nesse entendimento, a transformação da sociedade humana é, em si e para si, também transformação da natureza. Nem mais, nem menos.

Tudo isso coloca-nos frente a uma crítica radical ao senso mais ou menos comum de que o homem seria capaz de destruir a natureza ou de que a natureza teria, para nós, o sentido de alteridade (no contexto do ambientalismo, isso tudo nos levaria a pensar que a constante transformação da sociedade, enquanto transformação da natureza, resultaria em uma natureza onde a existência humana já não seria possível).

Um outro detalhe a se observar é a afirmação de que a frase proposta no programa de Gotha "encontra-se em todas as cartilhas e só é correta se se subentender que o trabalho é efetuado com os correspondentes objetos e Instrumentos". O caminho para tal observação, no entanto, é mais tortuoso. Teremos de revisitar um amplo embate do chamado “jovem Marx” em seus Manuscritos Econômicos e Filosóficos - trata-se da parte final do primeiro manuscrito, intitulada "O Trabalho Alienado".

\section{Segundo Movimento e as variantes em torno do conceito de alienação: os Manuscritos}

(...) o trabalho não produz somente mercadorias; ele produz a si mesmo e ao trabalhador como uma mercadoria, e isto na medida em que produz, de fato, mercadorias em geral (MARX, 2008, p. 80)

O trabalhador nada pode criar sem a natureza, sem o mundo exterior sensível. Ela é a matéria na qual o seu trabalho se efetiva, na qual (o trabalho) produz. (MARX, 2008, p. 81, grifos do autor) 
Em 1844, Marx tinha 26 anos quando escreveu os manuscritos que serão citados aqui e debatia-se com o legado de Hegel, com o qual deu início às suas reflexões políticas e, por que não dizer, filosóficas, econômicas etc. É na crítica a Hegel que Marx, para os limites deste nosso texto, refaz o caminho necessário à construção de uma nova leitura do significado de humanidade e de natureza, e o faz procurando, justamente, superar a maneira pela qual se entendiam a filosofia, a economia etc.

Considerando que a Crítica ao Programa de Gotha foi escrita em 1875 (trinta e um anos depois dos Manuscritos e sete anos depois da primeira edição do primeiro volume d'O Capital), as duas citações acima mostram que os seus fundamentos argumentativos já estavam desenvolvidos nos Manuscritos. A ideia central estava no fato de que a humanidade, ao mesmo tempo em que é uma das maneiras de materialização da natureza (como qualquer outro dos praticamente infinitos elementos que a compõem), ao se transformar é, igualmente, a materialização da transformação da natureza. Por outro lado, a transformação das sociedades humanas é, na sua realização material, a transformação da maneira pela qual os demais elementos que compõem a natureza igualmente se transformam ou são transformados enquanto, inclusive, objeto de trabalho humano. Está dado que esses elementos, estranhos ao homem por serem "o outro", ao mesmo tempo conosco se confundem e, exatamente por serem o outro e se tornando objeto e resultado do trabalho, se transformam em objeto "para nós".

Por isso mesmo, ao considerar "o trabalho fonte de riqueza sem levar em conta as ferramentas e as formas de organização do trabalho", o que teríamos é um trabalho genérico, metafísico, impossível de ser encontrado nas relações concretas da singularidade (humanidade) no interior da universalidade (natureza) e, portanto, no movimento da singularidade como realização do movimento universal.

É nesse sentido que natureza e humanidade são dimensões escalares de uma e mesma coisa, sem que se possa deixar de lado que, por ser parte, a humanidade é o "outro" em relação à natureza e, da mesma maneira, a natureza é a "outra" para a humanidade. Isso, no entanto, só se dá pela mútua alienação entre todo e parte, onde o estranhamento do homem em relação aos elementos que compõem o mundo sobre o qual e do qual ele vive, é o que permite que este os reconheça, deles se aproprie, com eles sobreviva e, transformando-os, transforme-se, porque "o outro" já não é mais o mesmo.

A vida genérica, tanto no homem como no animal, consiste fisicamente, em primeiro lugar, nisto: que o homem (tal qual o animal) vive da natureza inorgânica, e quanto mais universal é o homem que o animal, tanto mais universal é o domínio da natureza inorgânica da qual ele vive. Assim como plantas, animais, pedras, ar, luz, etc., formam teoricamente uma parte da consciência humana, em parte como objetos da ciência natural, em parte como objetos da arte - sua natureza inorgânica, meios de vida espirituais, que ele tem de preparar prioritariamente para a fruição e para a digestão formam também praticamente uma parte da vida humana e da atividade humana. Fisicamente o homem vive somente destes produtos da natureza, possam eles aparecer na forma de alimentos, 
aquecimento, vestuário, habitação etc. Praticamente, a universalidade do homem aparece precisamente na universalidade que faz da natureza inteira o seu corpo inorgânico, tanto na medida em que ela é 1) um meio de vida imediato, quando na medida em que ela é o objeto/matéria e o instrumento de sua atividade vital. A natureza é o corpo inorgânico do homem, a saber, a natureza enquanto ela mesma não é o corpo humano. O homem vive da natureza significa: a natureza é o seu corpo. Com o qual ele tem de ficar num processo contínuo para não morrer. Que a vida física e mental do homem está interconectada com a natureza não tem outro sentido senão que a natureza está interconectada consigo mesma, pois o homem é uma parte da natureza.

$\mathrm{Na}$ medida em que o trabalho estranhado estranha do homem a natureza, [e o homem] de si mesmo, de sua própria função ativa, de sua atividade vital; ela estranha do homem o gênero [humano]. Fazlhe da vida genérica apenas um meio da vida individual. (MARX, 2008 , p. 84 , grifos do autor)

A citação é longa, mas inevitável. Em uma leitura rápida, pode-se afirmar que o texto de Marx está aí somente para confirmar o que já escrevi sobre ele. Independentemente disso, creio que vale realçar o desdobramento que aqui se realiza. $\mathrm{O}$ primeiro ponto está associado à afirmação de que o animal homem é mais universal que os demais - o que, imediatamente, impõe a observação de que a dinâmica social, que é transformação da natureza, também se observa do ponto de vista geográfico. À medida em que se realiza esse processo de apropriação, transformação, redefinição dos elementos entre si, o lugar do homem no planeta redefine igualmente a escala do ecúmeno humano e, por conseguinte, a complexidade da variedade dos elementos e dos processos de trabalho que o definem. A magistral proposição de Lefebvre de que "No princípio era o Topos" tem aqui seu ponto mais importante de inflexão. Trata-se, portanto, de uma redefinição constante da geograficidade e de todos os elementos que compõem a natureza, o que nos tem permitido reler os fundamentos epistemológicos do discurso geográfico contemporâneo.

O desdobramento da reflexão que "chama para o debate" a noção de trabalho alienado é, sem dúvida, a maneira pela qual Marx coloca o pensamento hegeliano no campo do materialismo: a alienação é, aqui, o ato próprio de, ao fundir-se com os elementos (matérias primas, ferramentas e habilidades), resultar em um novo objeto, uma nova natureza, alimentando novamente a presença do outro, do estranho, do estranhamento que se faz como objeto alienado na condição de ser o novo formato da simbiose homem-natureza, isto é, entre a parte e o todo - e, o que não é o mesmo, entre o todo e a parte.

O embate, como já foi indicado, tomará o caráter de transversalidade em toda a obra de Marx e, de diferentes maneiras, vamos encontrá-lo substanciado na sua assim denominada teoria do valor e, portanto, definindo os parâmetros utilizados na elaboração d'O Capital. 


\section{Terceiro Movimento: a Síntese de Múltiplas Determinações}

Entre 1857 e 1858 (portanto, muitos anos antes da crítica ao Programa de Gotha), Marx escreveu uma série de anotações que ficou conhecida como os Grundrisse (algo como "borrador") e que é reconhecida como o conjunto de exercícios que antecedeu a elaboração d'O Capital. Das milhares de páginas que compõem o "Borrador", tomei aqui como referência alguns pequenos trechos de um capítulo intitulado "O Método em economia política" (quase uma digressão de caráter metodológico), que se encontra entre outros dois centrados no tema da produção ("A Relação Geral entre produção, distribuição e consumo" e "Produção. Meios de Produção e relações de produção").

No sentido de evitar muitas e longas citações, vale adiantar que o texto se inicia colocando em questão a necessidade, para aqueles que fazem análises no campo da economia-política, de partir do concreto (a possibilidade de Marx considerar tal atitude relativamente comum em grande parte da produção intelectual é quase uma obviedade). De toda maneira, o problema reside no fato de que ter o concreto como ponto de partida (independentemente do que se considere como concreto) é uma incorreção do ponto de vista metodológico, pois ao tentar compreendê-lo nos perderemos em sua descrição e na identificação dos elementos que, por compô-lo, parecem ser seus elementos explicativos fundamentais. É por isso que Marx afirma que:

(...) do concreto representado [chegaria] a conceitos abstratos [Abstrakta] cada vez mais finos, até que tivesse chegado às determinações mais simples. (...). [Acontece, no entanto, que] $\mathrm{O}$ concreto é concreto porque é a síntese de múltiplas determinações, portanto, unidade da diversidade. Por essa razão, o concreto aparece no pensamento como processo da síntese, como resultado, não como ponto de partida, não obstante seja o ponto de partida efetivo e, em consequência, também o ponto de partida da intuição e da representação. (...) Mas de forma alguma é o processo de gênese do próprio concreto. (MARX, 2011, p. 77-78)

Temos de considerar em meio a tantas proposições que, como ponto de partida, o conhecimento dos sujeitos se resume ao sensório e que, à medida que o sensório se apropria desse processo contínuo de simbiose e alienação imposto pela sobrevivência, caberá ao sujeito transformar o concreto em conceito. Assim, em outras palavras, o vivido é a condição que define o "estar vivendo". Assim reconhecemos as ações já vividas como conhecimentos prévios e os desafios ainda desconhecidos ou não percebidos como, justamente, a nossa ignorância. Ocorre, como um adendo desse processo, que parte considerável do que reconhecemos como o "já vivido" de fato foi apropriado nas relações sociais em que estamos inseridos. Dessa maneira, trata-se muito mais da experiência coletiva (nos dias de hoje, para a maioria de nós, na escala da civilização planetária) e, portanto, o vivido deixa de ser uma questão meramente pessoal para ser o domínio do sujeito em relação ao jogo simbólico que define a memória da sociedade a que pertence. Vale lembrar que se apropriar da experiência da sociedade que pertencemos pouco ou nada se associa ao domínio de sua História, mas sim ao fato de que todo o conjunto de 
atos que permite a sobrevivência e reprodução de uma sociedade já é, em si mesmo, a síntese possível dessa mesma História.

A ideia de que o concreto é concreto porque é síntese de múltiplas determinações obriga-nos, sempre, a perguntar se o reconhecimento das determinações nos permitiria saber o que é, de fato, o concreto. Ficaríamos, então, presos nas armadilhas da dúvida hiperbólica cartesiana e as determinações tornar-se-iam uma infinidade de "concretos" cuja identificação seria impossível e tornaria igualmente impossível ao homem o ato do pensar, isto é, do construir o "concreto em pensamento". Vejamos:

Por essa razão, para a consciência para a qual o pensamento conceitualizante é o ser humano efetivo, e somente o mundo conceituado enquanto tal é o mundo efetivo - e a consciência filosófica é assim determinada -, o movimento das categorias aparece, por conseguinte, como o ato de produção efetivo - que, infelizmente, recebe apenas um estímulo do exterior -, cujo resultado é o mundo efetivo; e isso - que, no entanto, é uma tautologia - é correto na medida em que a totalidade concreta como totalidade de pensamento, como um concreto de pensamento, é $\mid$ de fato um produto| do pensar, do conceituar; mas de forma alguma é um produto do conceito que pensa fora e acima da intuição e da representação, e gera a si próprio, sendo antes produto da elaboração da intuição e da representação em conceitos. (MARX, 2011, p. 7879).

Como se observa, o embate contra o empirismo e, na mesma linha de fogo, contra a metafísica, reconhece a capacidade humana de construir conceitos, sem deixar de lado o fato de que tal capacidade está associada ao exercício que se realiza entre o sujeito e seu mundo e, nesse movimento, o já sabido e o processo do aprender, o já pensado e o processo do pensar, enfim, o já vivido e o processo do viver; dessa maneira, também o ato de pensar é um ato do concreto que se quer pensar enquanto sujeito e enquanto objeto do pensamento.

Há aqui uma espécie de mergulho, algo vertiginoso e no contraponto do legado deixado por Kant e da crítica elaborada por Hegel ao subjetivismo (defendendo, nessa proposição, a tese de que Kant sistematizou magistralmente a chamada civilização ocidental na sua mais profunda crise para a época, isto é, a necessária negação do mundo mercantil e sua cultura sem, no entanto, conseguir livrar-se dela, enquanto Hegel apontou para o futuro e pressupôs o ratio da sociedade fabril que se consolidava). Acompanhando tal caminho há aqui a radicalidade de se propor que, do ponto de vista de Marx, a natureza pensa, e retomo aqui ao ponto de partida desse artigo, onde se identifica que a relação da humanidade com a natureza é uma relação entre parte e todo na qual, sempre, a transformação da parte é transformação do todo e a transformação do todo se realiza, igualmente, na transformação de suas partes. 


\section{E Engels? O prefácio do Dialética da Natureza}

Debruçar-se sobre as proposições de Engels é, sob alguns aspectos, algo ainda mais difícil que refletir sobre as proposições de Marx. O problema mais grave, como sempre, está na multiplicidade de posicionamentos de seus comentadores e, principalmente, no fato de alguns deles terem utilizado um tom acusatório ao afirmar que o companheiro de Marx não seria, de fato, marxista. Acusado de não ter superado o positivismo clássico, ou mesmo os dilemas mais comuns do Iluminismo, Engels tem no mínimo sido colocado como um ator secundário no processo de construção da tradição marxista e, no limite, houve evidentes esforços no sentido de excluí-lo, como um verdadeiro pária. Acontece que, tal como já comentamos acerca da relação deste artigo com o batalhão de exegetas que já comentaram os fundamentos da obra de Marx, deixarermos de lado esse embate ${ }^{1}$.

Dialética da Natureza é uma obra inacabada escrita em 1883, o que coincide com o ano da morte de Marx. De toda maneira, trata-se de um projeto que teve seu início no embate do autor com Eugen Duhring, publicado pela primeira vez em 1878. Anti-Duhring, nome que recebeu a obra na sua tradução brasileira, já apontava o inconformismo de Engels com relação a comentários simplificadores do pensamento científico no século XIX e tais reflexões poderão ser evidenciadas, igualmente, no seu opúsculo $O$ papel do trabalho na transformação do macaco em homem, além de apontamentos feitos em conjunto com Marx no Ideologia Alemã e no Manifesto Comunista.

O prefácio ao Dialética da Natureza, por sua vez, não é mais que uma visão geral sobre o desenvolvimento das pesquisas nos campos da Física, Química, Biologia e Antropologia. Em um arroubo quase apaixonado, Engels se refere àqueles que fundaram a sociedade burguesa nos seguintes termos:

Foi essa a maior revolução progressista que a humanidade havia visto até então, uma época que precisava de gigantes e, de fato, engendrou-os; gigantes em poder de pensamento, paixão, caráter, multilateralidade e sabedoria. Os homens que estabeleceram o moderno domínio da burguesia eram alguma coisa em quase nada limitados pelo espírito burguês ${ }^{2}$. (ENGELS, 1979, p. 16).

$\mathrm{Na}$ sequência, citando homens como Leonardo da Vinci, Maquiavel e Dürer, o texto prossegue procurando evidenciar o papel reacionário das religiões. Observemos a maneira como Engels entende o processo:

Mas o que constituía sua principal característica era que quase todos
participavam ativamente das lutas práticas de seu tempo, tomavam
partido e lutavam, este por meio da palavra e da pena, aquele com a

\footnotetext{
${ }^{1}$ Deixemos como referência que, no nosso entender, a obra de João Maria de Freitas Branco, intitulada Dialética, Ciência e Natureza, já tomou o tema para si e, sem grandes dificuldades, demonstrou que ele é improcedente.

${ }^{2}$ A tradução espanhola disponibilizada pelo Kindle traz um texto mais claro quanto ao sentido: "Los hombres que fundaron la moderna dominación de la burguesía eran todo menos gentes burguesamente limitadas." ENGELS, F. Dialéctica de la Naturaleza (Spanish Edition). Editorial Medí. Edición de Kindle.
} 
espada, muitos com ambas. Daí essa plenitude e força de caráter que fazia deles homens completos. Os sábios de gabinete são exceção: ou eram pessoas de segunda ou terceira classe, ou prudentes filisteus que temiam queimar os dedos.

Assim também a investigação da Natureza evoluía então, acompanhando a revolução geral, e era, por seu turno, inteiramente revolucionária, uma vez que era forçada a lutar pelo seu direito à existência. Ao lado dos grandes italianos, iniciadores da filosofia moderna, a investigação da Natureza forneceu alguns mártires, levados à fogueira ou aos cárceres da Inquisição. É bastante significativo o fato de que os protestantes sobrepuseram-se aos católicos no que se refere à perseguição à livre investigação da Natureza. Calvino mandou queimar Miguel Servet, quando este estava prestes a descobrir a circulação do sangue, determinando que fosse assado lentamente, durante duas horas, ao passo que a Inquisição se contentava com, apenas e simplesmente, queimar Giordano Bruno. (ENGELS, 1979, p. 16-17).

Algumas páginas mais à frente (p. 19), Engels identifica o crucial papel de Kant que, em $1755^{3}$ publica o seu História Natural e Teoria Geral sobre o Céu e elimina da discussão a ideia de um "primeiro impulso". Assim, o texto de Engels prossegue resumindo um amplo conjunto de descobertas e proposições em diferentes campos do conhecimento até que, à maneira do que já havia constatado no Manifesto do Partido Comunista, novamente realça o que, para ele, seria uma das principais expressões resultantes da assunção da dialética como fundamento lógico para se pensar o mundo justamente porque é dessa maneira que o próprio mundo funciona. Vale observar a maneira pela qual Engels aborda a questão:

Dessa maneira, o abismo entre a Natureza orgânica e inorgânica ficava reduzido a um mínimo, sendo eliminada uma das principais dificuldades que se opunham, até então, à teoria da transformação progressiva de todos os organismos. A nova concepção de natureza ficava, assim, configurada em suas linhas gerais: tudo aquilo que se considerava rígido, se havia tornado flexível; tudo quanto era fixo, foi posto em movimento; tudo quanto era tido por eterno, tornou-se transitório; ficara comprovado que toda a Natureza se movia num eterno fluxo e permanente circulação. (ENGELS, 1979, p. 22-23).

Até que retornamos, finalmente, ao ponto central deste artigo: a relação homem - natureza, ou melhor, natureza - homem, ou ainda, tal como já observamos, a maneira

\footnotetext{
${ }^{3}$ Vale lembrar que tais proposições surgiram como uma resposta da filosofia à inexplicável maneira pela qual Deus teria castigado um dos povos mais católicos do mundo ao praticamente destruir Lisboa com um violento terremoto e, logo a seguir, com um monstruoso tsunami. O objetivo geral seria retirar das mãos da divindade a responsabilidade sobre tais incidentes e demonstrar que somente o conhecimento da natureza poderia preservar o homem de determinados comportamentos cuja origem e dinâmica nos eram desconhecidos. De toda maneira, Kant chega a propor a necessidade de se constituir uma espécie de Geofísica e passa a dar aulas de Geografia. Segundo se sabe, depois da lógica, a Geografia foi o segundo tema mais tratado por Kant em seu copioso trabalho na universidade de Konigsberg.
} 
pela qual se entendeu a relação entre o todo e uma de suas partes. Tendo como ponto de partida a formação das primeiras células (a qual, segundo Engels (1979, p. 25), já "representava a constituição de todo o mundo orgânico", o texto vai tomando o rumo geral já dado por Lineu e, posteriormente, Darwin. Ao final do parágrafo, Engels brinda-nos com a seguinte afirmação: "em último lugar, o animal em que o sistema nervoso atinge o desenvolvimento mais completo - a dos vertebrados -; e finalmente, entre eles, o vertebrado em quem a Natureza adquire consciência de si mesma: o homem." (ibid., p. 25).

Temos, então, o fundamento geral da reflexão - o homem é a natureza que toma consciência de si própria ${ }^{4}$, ou, em outras palavras, o homem, no sentido de humanidade, é uma maneira de realização da própria natureza e, nesse sentido, observamos que a proposição de Engels, apesar de construída sobre um conjunto de argumentos de origem muito diferente, dialoga diretamente com o que já havia sido proposto por Marx desde seus Manuscritos Econômicos e Filosóficos

As aproximações entre os dois pensadores tomam formato mais definitivo no parágrafo seguinte, em que Engels reflete sobre:

A especialização da mão: ela significa a ferramenta; a reação transformadora do homem nobre a Natureza, sobre a produção. Também os animais, entendidos num sentido limitado, possuem ferramentas; mas apenas como membros de seu corpo (...). Há também animais que produzem, mas sua influência produtiva sobre a Natureza circundante é igual a zero. Unicamente o homem conseguiu imprimir seu selo sobre a natureza, não só trasladando plantas e animais, mas modificando também o aspecto, o clima de seu lugar de habitação. (...) Mas ao lado da mão, se desenvolveu passo a passo o cérebro, tendo aparecido a consciência, primeira das condições necessárias para serem alcançados determinados efeitos práticos úteis; e, mais tarde, entre os povos mais favorecidos, e resultante dela, a penetração e investigação das leis naturais que os condicionam. (ENGELS, 1979, p. 25-26).

Assim, imaginando que o pensar dialético é a condição de se apropriar da dialética da natureza, Engels acaba por fundir numa mesma discussão tanto o conjunto de leituras que se pode fazer sobre a realidade (isto é, as noções de biologia, química, física, antropologia etc.) quanto o fato de que todas essas variantes fundem-se num mesmo mundo, num mesmo fenomênico. Se me permite a imagem geométrica (e, portanto, perigosamente simplificadora), há aqui uma fusão que tem como ponto de partida a fragmentação dos discursos (uma certa horizontalidade) e o como tudo isso, independentemente da escala da discussão, coloca sempre a humanidade no centro das preocupações (uma certa verticalidade).

\footnotetext{
${ }^{4}$ Vale lembrar que a proposição não é exclusiva de Engels. De memória, citaria Elisée Reclus, que muitos anos antes afirmava a mesma coisa.
} 


\section{E a Geografia?}

Do ponto de vista das tradições mais recentes (século e meio, se tanto) da Geografia tais proposições são, no mínimo, explosivas. No seu sentido mais geral, o que está em jogo é a fragmentação do conhecimento em ciências da natureza e ciências das humanidades. Nesse contexto valeria propor que todas as ciências são ciências da natureza e que a diferença entre elas está na construção da dúvida: o sujeito que procura respostas deve identificar a partir de qual relação entre parte e todo ele se questiona e de que ferramentas conceituais necessita para buscar suas respostas. Assim, desdobrando um pouco mais a proposição, valeria afirmar que todo questionamento que se debruça sobre a parte sem considerar o todo é pura metafísica e, tal como Marx propõe nos Grundrisse, é uma proposição vazia de sentido. Discutir a sociedade humana como algo para além da natureza é identificar uma sociedade que, de fato, simplesmente não existe e, retomando o já dito, é o mesmo que discutir trabalho por fora do ato de trabalhar, o pensamento por fora do ato de pensar, ou a circulação atmosférica por fora dos processos gerais de desflorestamento ou de asfaltamento das grandes cidades em associação com a diferencialidade na distribuição de energia, relacionada à presença ou ausência de luz solar no interior do processo geral de rotação e translação do planeta, e assim por diante.

A Geografia, no seu embate com a fragmentação técnica do trabalho intelectual e os desdobramentos corporativos advindos da ordenação de tais trabalhos no interior das universidades e centros de pesquisa, subordinou-se, principalmente na França, aos dilemas do iluminismo. Com uma ideia simplificadora do significado de conhecimento ou de ciência ou, ainda, do estar ciente que tal discussão nos aponta, coloca-se em questão se há ou não cientificidade em discutir a maneira pela qual as sociedades humanas se organizam. A ideia de uma Geografia física em contraponto a uma Geografia humana tem os mesmos fundamentos que levaram os trabalhadores em Gotha a imaginar que o trabalho é a fonte de toda riqueza.

Mais recentemente, dedicamo-nos a imaginar a possibilidade de transformar a Geografia numa espaciologia ou, no mesmo patamar de puerilidade, reduzir a questão metodológica a uma contradição entre fixos e fluxos. Assim, confundimos um dos aspectos fundamentais do fenomênico (espaço) com um estatuto epistemológico que trata de construir dúvidas e respostas ao contínuo dilema da localização dos elementos que compõe um ou mais processos na definição de suas dinâmicas. Igualmente, abandonamos a grande lição de Galileu: tudo se move e a percepção de que um objeto se encontra em repouso é, somente, o fato de estarmos observando algo que se move na mesma direção e velocidade de seu observador. Assim, deixamos de lado que a dinâmica que nos permite identificar o sentido topológico dos processos, diferentemente da saída Newtoniana (que teve de identificar um espaço fixo para reconhecer o movimento), obriga-nos sistematicamente a avaliar o contraponto dos fluxos que se contrapõem e se contradizem, se negam para que possam se afirmar enquanto processo.

Nesse sentido, e com o objetivo de finalizar esta reflexão, o que se identifica é que nos perdemos frente à natureza mesma do conhecimento e escolhemos o caminho dos idealismos (mais ou menos objetivos, mais ou menos subjetivos) para construirmos uma 
noção de natureza que não se confunde com a totalidade, mas aparece como contraponto e externalidade do humano. É nesse ponto que a ontologia que se desdobra de nosso pensar carece, de fato, da existência de um ser.

\section{Referências}

BRANCO, J. M. F. Dialética, Ciência e Natureza. Lisboa: Ed. Caminho, 1989.

ENGELS, F. Anti-Düring. Rio de Janeiro: Paz e Terra, 1976.

ENGELS, F. Dialética da Natureza. 3. ed. Rio de Janeiro: Paz e Terra, 1979.

ENGELS, F. Sobre o Papel do Trabalho na Transformação do Macaco em Homem. In: MARX, K.; ENGELS, F. Obras Escolhidas. v. 2. São Paulo: Alfa-Ômega, s/d (b), p. 267-280

ENGELS, F. A Origem da Família, da Propriedade Privada e do Estado. São Paulo, Editora Centauro, 2002

MARX, K. Crítica ao programa de Gotha. Rio de Janeiro: Livraria Ciência e Paz, 1984.

MARX, K. Manuscritos Econômico-Filosóficos. São Paulo: Boitempo, 2008.

MARX, K. Grundrisse. Manuscritos econômicos de 1857-1858: esboços da crítica da economia política. São Paulo: Boitempo. 2011.

MOREIRA, Ruy. O Movimento Operário e a Questão Cidade Campo no Brasil. Rio de Janeiro: Vozes, 1985.

* Um outro título possivel, com base em uma inspiração provocada por Ruy Moreira, seria: A Busca de uma Geografia dos Homens Concretos (Ruy utiliza a expressão "História dos homens concretos". Veja Moreira, 1985).

Douglas Santos

Doutor em Ciências Sociais pela Pontifícia Universidade Católica de São Paulo, mestre em Geografia Humana pela FFLCH-USP, professor colaborador do Programa de Pós-Graduação em Geografia da Universidade Federal da Grande Dourados; professor visitante da Escola Doutoral da Universidade Pedagógica de Moçambique;

Calle de la Canoa, 43 (bajo 1) Madrid, Madrid - CP 28042

Email: douglassangeog@gmail.com 